Santa Clara University

Scholar Commons

Physics

College of Arts \& Sciences

$3-2016$

\title{
Structure-function relationships of fullerene esters in polymer solar cells: unexpected structural effects on lifetime and efficiency
}

Michael Tro

Alexis Sarabia

Kyle J. Bandaccari

David Oparko

Emma Lewis

See next page for additional authors

Follow this and additional works at: http://scholarcommons.scu.edu/physics

Part of the Biochemistry, Biophysics, and Structural Biology Commons, and the Physics Commons

\section{Recommended Citation}

Tro, M., Sarabia, A., Bandaccari, K. J., Oparko, D., Lewis, E., Giammona, M. J., ... McNelis, B. J. (2016). Structure-function relationships of fullerene esters in polymer solar cells: unexpected structural effects on lifetime and efficiency. International Journal of Energy Research, 40(4), 507-513.

This is the peer reviewed version of the following article: Tro, M., Sarabia, A., Bandaccari, K. J., Oparko, D., Lewis, E., Giammona, M. J., ... McNelis, B. J. (2016). Structure-function relationships of fullerene esters in polymer solar cells: unexpected structural effects on lifetime and efficiency. International Journal of Energy Research, 40(4), 507-513, which has been published in final form at https://doi.org/10.1002/er.3463. This article may be used for non-commercial purposes in accordance With Wiley Terms and Conditions for self-archiving.

This Article is brought to you for free and open access by the College of Arts \& Sciences at Scholar Commons. It has been accepted for inclusion in Physics by an authorized administrator of Scholar Commons. For more information, please contact rscroggin@scu.edu. 


\section{Authors}

Michael Tro, Alexis Sarabia, Kyle J. Bandaccari, David Oparko, Emma Lewis, Maxwell J. Giammona, Justin

Isaac, Parisa Tajalli-Tehrani Valverde, Grace E. Chesmore, Thorsteinn Adalsteinsson, Richard P. Barber Jr., and Brian J. McNelis 
Effect of electron acceptor structure on stability and efficiency in polymer solar cells: a combinatorial approach

Michael Tro ${ }^{1}$, Alexis Sarabia ${ }^{1}$, Kyle J. Bandaccari ${ }^{1}$, David Oparko² ${ }^{2}$ Emma Lewis ${ }^{2,3}$, Maxwell J. Giammona $^{1}$, Justin Isaac ${ }^{2}$, Parisa Tajalli-Tehrani Valverde ${ }^{1}$, Grace E. Chesmore ${ }^{2,3}$, Thorsteinn Adalsteinsson ${ }^{1,3}$, Richard P. Barber, Jr. ${ }^{2,3}$ and Brian J. McNelis ${ }^{1 *}$

${ }^{I}$ Department of Chemistry and Biochemistry, Santa Clara University, Santa Clara, CA 95053, USA

${ }^{2}$ Department of Physics, Santa Clara University, Santa Clara, CA 95053, USA

${ }^{3}$ Center for Nanostructures, Santa Clara University, Santa Clara, CA 95053, USA

*Corresponding author.Tel.:+1 408554 4797; Fax:+1 4085547811.

E-mail address: bmcnelis@scu.edu (B.J. McNelis).

\begin{abstract}
We report both transport measurements and spectroscopic data of polymer/fullerene blend photovoltaics using a small library of fullerene esters to correlate device properties with a range of functionality and structural diversity of the ester substituent. We observe that minor structural changes can lead to significant differences in device efficiency and lifetime. Surprisingly, we have found that isomeric Rgroups in the fullerene ester-based devices we have studied have very different efficiencies. The characteristic lifetimes derived from both transport and spectroscopic measurements are generally comparable, however some more rapid effects in specific fullerene esters are not observed spectroscopically. Our results support using a library approach for optimizing device performance in these systems.
\end{abstract}




\section{Introduction}

After two decades, polymer photovoltaics continue to be widely investigated given their potential to provide an inexpensive alternative to Si-based technologies. Such solar cells would be relatively easy to fabricate and would not compete for an increasingly expensive raw material commodity [1]-[11]. Despite this promise, two major obstacles in the implementation of these materials into commercially-available solar cells exist: relatively poor power conversion efficiencies ( $\eta$ 's) and short device lifetime. To date the bulk of research has focused on device fabrication and synthesis of polymers to improve efficiencies, which have been optimized at $9 \%$ or higher [2], [3], [10], [11]. While lower device efficiency could be considered a tradeoff with decreased cost of the polymer-based devices, lifetime is a critical characteristic in determining the viability of organic photovoltaics. In order to advance the technology to the commercial product stage, the stability of these devices must be improved.

A commonly studied organic photovoltaic system utilizes poly(3-hexylthiophene-2,5-diyl) (P3HT) as the photon induced electron donor (Fig. 1). The typical organic electron acceptor is Buckminster fullerene, $\left(\mathrm{C}_{60}\right)$. Unmodified fullerenes have very poor solubilities in most organic solvents and tend to form clusters and aggregates, even in solution [12]-[16]. The fullerenes of choice for organic photovoltaics are appended with alkyl chains to improve solubility [13]. An example is [6,6]-phenyl- $\mathrm{C}_{61}$-butyric acid methyl ester, or PCBM. Other esters of the $[6,6]-$ phenyl- $\mathrm{C}_{61}$-butyric acid are commonly abbreviated as PCB-alkyl derivatives. In previous experiments in our laboratories alternative electron acceptors were synthesized including [6,6]Phenyl $\mathrm{C}_{61}$ butyric acid octadecyl ester (PCBOD, 1a) [17] and [6,6]-phenyl $\mathrm{C}_{61}$ butyric acid octyl ester (PCBO, 1b) [18] (Fig. 1). Based on detailed results for PCBOD and preliminary ones for PCBO, we have produced a more diverse set of PCB-alkyl esters and measured the figures of 
merit for photovoltaic devices using these additives.

A critical parameter for these devices is blend stoichiometry. We characterize our samples using $\mathrm{C}_{60}$ mole fraction $x$ where

$$
x=\frac{m_{C 60} / M W_{C 60}}{m_{C 60} / M W_{C 60}+m_{P 3 H T} / M W_{P 3 H T}}
$$

with $M W$ denoting the molecular weight of each species, $m$ denoting its mass and $\mathrm{C}_{60}$ referring to the functionalized fullerene molecule under investigation. For the electron donor (in this expression P3HT), we use the monomer molar mass. In other words, $x=0.5$ represents a blend with one $\mathrm{C}_{60}$ molecule per P3HT monomer [17]-[19]. The standard widely used in the literature is equal weight concentrations of PCBM:P3HT, which corresponds to $x=0.16$. While the equalweight ratio might serve as a simple starting point for initial experiments using new materials, it is at best cumbersome when we compare fullerene-polymer blends using different fullerenes with different molecular weights. Our opinion is that mole fraction clearly establishes the ratio of fullerene-to-monomer units in the polymer and that mole fraction should be reported for polymer-fullerene devices.

In our solar cells studies of PCBOD 1a and PCBO 1b, we observe a fourfold increase in power conversion efficiency for PCBO over PCBOD, albeit at $140^{\circ} \mathrm{C}$ anneal temperatures [18]. For both PCBM and PCBOD, we observed the best efficiency and lifetime with $195^{\circ} \mathrm{C}$ anneals: a temperature just below the melting point for P3HT [20]. Before our initial PCBO results, a reasonable conclusion would have been that the optimum anneal temperature is a characteristic dictated by the polymer. The significantly lower anneal temperature for the PCBO suggests that 
this simple picture is inadequate and that a more detailed investigation is needed. These findings motivated us to produce a small library of fullerenes.

Combinatorial approaches have been reported recently to optimize parameters of polymer photovoltaics [21], [22]. In one study, novel MEH-PPV analogs were prepared and the fullerene structure analyzed for optimal device performance [23]. They found that with different conducting polymers there are specific fullerene structures that maximize efficiency with each polymer they studied. These paired polymer-fullerene combinations demonstrate that changing components of the blend requires re-optimization of fabrication and constituent structure selection.

We prepared simple alky1 chain esters and some functionalized side chains to examine the device lifetime and efficiency vs. R-group chain length and functionality. We use a simple transesterification method to prepare the fullerene esters $\mathbf{1 c - i}$ as shown in Scheme 1 [24]. Following we present efficiency and lifetime results for these new fullerenes in addition to a more complete data set for PCBO (not previously reported).

\section{Experimental}

Samples are fabricated in an MBraun inert nitrogen atmosphere glove box using patterned indium-tin-oxide (ITO) coated glass substrates. ITO serves as the transparent hole-injection electrode. A spin-cast planarizing layer of poly[3,4-ethylenedioxythiophene]:poly[styrenesulfonate] (PEDOT:PSS) is followed by the organic active layer. After spin-casting, the sample is annealed for one hour in the glove box. The electron-injecting contact is fabricated in a bell jar evaporator from a patterned layer of $\sim 2 \mathrm{~nm}$ thick lithiumfluoride (LiF) followed by $100 \mathrm{~nm}$ of aluminum (Al) deposited on top of the organic layer by 
shadow mask thermal evaporation. As the evaporator is not integrated into the glove box, samples are transferred between the two using a vacuum tight vessel carrying dry nitrogen atmosphere. The elapsed time that samples are exposed to ambient air before contact deposition is typically under 5 minutes.

Electrical transport measurements are conducted in ambient atmosphere immediately after completing the sample preparation. Current-voltage ( $I-V$ ) characteristics of the devices are measured alternately in darkness and under illumination by a PV Measurements, Inc. Small-Area Class-B Solar Simulator. Automated transport data collection utilizes a MATLAB controlled routine via an IEEE 488 Bus interfaced Keithley 2400 SourceMeter. UV-vis measurements are performed using a Varian Cary 50 spectrometer. Samples are measured over periods of hours or days for both spectroscopic and transport experiments. Illumination is used only during the actual measurements; otherwise the samples remain in ambient but low light conditions for transport or dark conditions inside the spectrometer during spectroscopy. The laboratory temperature was controlled at $23-26^{\circ} \mathrm{C}$ with a relative humidity range of $50-70 \%$ (not directly controlled). Fig. 2 shows a schematic of the device architecture for electrical transport measurements. Spectroscopic studies were performed on samples without ITO or Al contacts.

\section{Results and Discussion}

Fig 3 shows a typical set of transport curves. $I-V$ measurements are normally recorded in 10-30 minute intervals depending on the apparent rate of change, and many interleaving curves were removed from this figure for clarity. This particular sample was a PCBO blend, however all the various samples yielded similar results, albeit at differing current scales. The inset of this 
figure shows the calculated power conversion efficiency as a function of time $\eta(t)$. As $\eta(t)$ appears linear in a semilog plot, it is apparent that it follows an exponential decay $\eta(t)=\eta(0) \exp (-t / \tau)$ where a characteristic (1/e) time $\tau$ can be derived from the slope $(-1 / \tau)[17]$. Such a slope is shown in the Fig. 3 inset. We chose to define this value as the characteristic "lifetime" for our sample.

Fig. 4 summarizes our results for PCBO:P3HT devices. As previously observed in the preliminary data, samples annealed at $140{ }^{\circ} \mathrm{C}$ were superior to those annealed at $195^{\circ} \mathrm{C}$. Our previous experiments had shown that for both PCBM and PCBOD (octadecyl chain) samples show the best efficiency and lifetime after being annealed at $195^{\circ} \mathrm{C}$. It is appealing to conclude that since these rather different PCB-esters are optimized at the same anneal temperature; the polymer is the constituent that controls this condition. The melting temperature for $\mathrm{P} 3 \mathrm{HT}$ is given as $218^{\circ} \mathrm{C}$ [20]. The fact that our PCBO samples do not optimize at this temperature indicate that there is more complexity to this aspect than originally understood. That this result persisted after a more thorough investigation motivated us to produce and study a broader array of PCB-esters. We have now further explored the structure-function relationships of various fullerene esters (shown in scheme 1) and the effects of R-group changes on device efficiency and lifetime.

Fig 5 shows the comparisons of PCB-esters with various R-groups, directly comparing efficiency $(\eta)$, open circuit voltage $\left(V_{O C}\right)$ and lifetime $(\tau)$ for all the devices we have produced with these fullerene esters (nominal mole fraction $x=0.25$ ). Overall, the open-circuit voltages are 
comparable for the different esters, but there are some notable differences in both efficiency and lifetime.

The most surprising aspect of these results is that modest changes in R-group structure can have a dramatic affect on efficiency. The most significant change is the isomeric butyl vs. isobutyl esters, 1c vs. 1d, with the isobutyl being approximately three fold more efficient than butyl. Interestingly, isobutyl has a longer lifetime as well, which contradicts our previous findings with PCBM vs. PCBOD, in which we see a trade-off between efficiency and lifetime. The efficiency of butyl and isobutyl ester compared with the butynyl ester $\mathbf{1 e}$ is also unexpected in that the ester chain length is the same and the alkyne functionality does not dramatically change the polarity of the side chain (or add a chromophore) and yet the performance of the device is dramatically affected with a large decrease in efficiency for the butynyl 1e. The 2ethylbutyl ester $\mathbf{1 h}$ results correspond with the butynyl result in that a small change in structure (the addition of two carbons compared to butyl or isobutyl, but similar branching as the isobutyl) can dramatically decrease the efficiency of the device. The octanol-substituted ester $\mathbf{1 g}$ shows a two-fold decrease in efficiency as compared to PCBO and about a ten-fold decrease in lifetime. The addition of the hydroxyl functionality does change the polarity/solubility of $\mathbf{1 i}$ as compared to is closest structural analog PCBO, $\mathbf{1 b}$ (1i has appreciable solubility in methanol, PCBO is not soluble in methanol). In contrast to the other results in this series, the changes we observe in efficiency and lifetime for $\mathbf{1} \mathbf{i}$ are consistent with expectation that the more significant structural change would correspond to larger changes in device performance. This highlights an important feature of these results in that unexpected results can be obtained by examining "minor" structural modifications of the components in organic PV's. In our results, the magnitude of the change in efficiency and lifetime is roughly comparable for the fullerene esters we studied, yet 
the structural change is dramatically different; butyl vs. isobutyl or butyl vs. butynyl as compared to octyl vs. octyl-8-ol or octyl vs. octadecyl.

The isomeric nitrobenzyl esters, $\mathbf{1 f}$ and $\mathbf{1 g}$, are especially interesting in that these isomeric compounds have dramatically different lifetimes. In fact, the 4-nitrobenzyl ester-based device decays faster than any of our previously studied fullerene ester devices (time constants of roughly 6 minutes). Again, such a dramatic change is unexpected given such a simple structural modification. One of our interests in the 2-nitrobenzyl ester, 1f, was to use this ester as a photocleavable group that would allow us to study the fullerene acid in these devices by deprotecting the ester to form the carboxylic acid after device fabrication. Although ester cleavage could be an explanation for such a dramatic change in the device lifetime for the 4nitrobenzyl ester, the 2-nitrobenzyl is the more photochemically labile yet has a comparable lifetime to the other fullerene esters we have studied. Although we have not ruled out photochemical reaction of $\mathbf{1 g}$ as the cause of the rapid degradation, it is curious that the 2nitrobenzyl ester does not exhibit the same behavior.

Fig. 6 shows a comparison between the efficiency of the 2-nitrobenzyl ester $\mathbf{1 f}$ and 4nitrobenzyl ester 1g. Three separate samples of each are presented. A 6 minute lifetime curve (straight line) is shown for reference. We note that although the 4-nitrobenzyl ester $\mathbf{1 g}$ exhibits a very rapid decay in efficiency, that effect is followed by a much slower ( $\tau$ of roughly 300 minutes). This longer decay time is comparable to that of the 2-nitrobenzyl ester $\mathbf{1 f}$.

In our spectroscopic studies with PCBOD devices, we have established that the octadecyl chain has an effect on the polymer organization, decreasing the degree of crystallinity of the P3HT in the device and thus the efficiency of the device [18]. Since we observe that butyl and 
isobutyl ester chains are the highest efficiency devices in this series, with different efficiencies and lifetime figures of merit, we used our time-dependent UV-vis spectroscopic method to further characterize these film mixtures. The spectra of each and the changes developing over time are not significantly different from each other and are comparable to what we have observed with PCBM films [18]. The rate of change in the UV-vis spectra for each film maintains the same trend observed for transport results from device measurements for these two films.

In examining all of our spectral data, there are two regimes in which shorter chain fullerene ester-based films (octyl, butyl and isobutyl) produce UV spectra that are similar to the PCBM-based films but significant changes in ester chain length (octadecyl) produce films that are significantly thinner and absorb weakly in the 450-600 nm range, critical to device efficiency [18]. These results provide some broad guidelines with respect to fullerene ester structure selection. For device screening purposes, it would be useful to have a simple UV-vis "assay" that would be indicative film's efficiency but the spectroscopic changes over have time have closely correlated to the trends we observe in device lifetime measurements. As we gain more experience with the spectroscopy of these films, we are observing trends for higher performing devices although it is difficult to correlate smaller changes in efficiency to any specific spectroscopic changes for most of the esters we have studied.

The time-dependent spectroscopic results for the films containing both nitrobenzyl esters are consistent with the long time constant results observed in device studies (see Fig.6), however we were unable to observe any spectroscopic evidence for the rapid change in the 4-nitrobenzyl ester 1g. Fig 7. Shows typical UV-vis data. A notable feature that was ubiquitous in our data for was a kink or pause in the spectral changes after about 1400-1500 minutes has elapsed (1 day). 
This behavior occurred in almost all samples, including a similar effect for a sample that was aged in the inert atmosphere glove box. This latter result suggests a morphological or structural transition is occurring, since chemical transformation due to oxidation should be suppressed in a nitrogen atmosphere. Overall, the spectral evidence has served as a valuable characterization $\theta f$ tool for these fullerene ester films and the rate of spectroscopic change is consistent with the temporal trends in the transport measurements.

\section{Conclusions}

We have shown that unexpected findings are obtained by making minor perturbations in the structure of fullerene esters and observing the changes in the transport properties of solar cells. Our results show significant differences in the efficiency and lifetime of isomeric compounds in two different examples. Small structural changes such as an additional carbon or changes in the degrees of unsaturation also affect device performance. Although these results do not follow a "logical" pattern, the examination of small library of fullerene esters has clearly demonstrated the validity of using an array of compounds to determine structure-function relationships in organic photovoltaics. The library approach has been used to great effect in the development of pharmaceuticals, but has seen increasing use in materials research. We have demonstrated that this approach could be especially valuable in optimizing devices and that screening small libraries of compounds could yield the high performing devices required for field applications. Interestingly, this approach has recently been used to examine hole-conductor analogs in perovskite-based PV's where isomeric Spiro-OMeTAD analogs yielded devices with different efficiencies [25]. We conclude that applying this library approach would be a valuable tool in studying other thin-film photovoltaics. 
We acknowledge both G. Laskowski and G. Sloan for invaluable technical assistance. Funding was provided by a Santa Clara University IBM Faculty Research Grant, a Santa Clara University Sustainability Grant and a grant from IntelliVision Technologies. 


\section{Figure and Scheme Captions}

Fig. 1. Electron-donor and the two initial electron-acceptor molecules used in this study.

Scheme 1. Synthesis of fullerene esters $\mathbf{1 a - i}$

Fig. 2. Schematic of solar cell layers.

Fig. 3. Typical current-voltage (I-V) curves showing the degradation of a PCBO:P3HT device in ambient conditions. The arrow indicates the progression of time. Inset: a semilog plot of the power conversion efficiency of this device as a function of time in ambient conditions. The solid line fit shows the slope used to extract the characteristic time $\tau$.

Fig. 4. Efficiency and lifetime and data from a series of PCBO:P3HT devices. We plot a) the initial power conversion efficiency $\eta$ and b) the decay time constant $\tau$ as a function of PCBO mole fraction (see Fig. 3 discussion). The different symbols refer to the anneal temperature for each device. Mean values are shown for $140{ }^{\circ} \mathrm{C}$ annealed (optimized) samples.

Fig. 5. Figures of merit for seven different fullerene structures, PCB-esters 1c-i. Plotted are a) the initial power conversion efficiency $\eta$, b) the open circuit voltage $V_{O C}$ and c) the decay time constant $\tau$ for the fullerenes with esters indicated along the abscissa. The overall average values for each measurement are displayed as the gray circles.

Fig. 6. Power conversion efficiency vs. time for 2-nitrobenzyl ester $\mathbf{1 f}$ and 4-nitrobenzyl ester $\mathbf{1 g .}$ Note the initially rapid degradation of the 4-nitrobenzyl ester followed by a much slower rate consistent with that of the 2-nitrobenzyl ester. 
Fig.7. UV-vis absorption spectroscopy for a 2-nitrobenzyl ester, 1f, sample: a) the initial and final absorbance, b) the differential absorbance taken at 15 minute intervals and c) the time dependence of the $554 \mathrm{~nm}$ absorption peak (every other data point removed for clarity). An exponential fit for the first 1500 minutes yields a time constant consistent with those derived from transport data (Fig. 6). 


\section{References}

[1] C. J. Brabec, V. Dyakonov, J. Parisi, and N. S. Sariciftci, Eds., Organic photovoltaics: concepts and realization. New York: Springer, 2003.

[2] B. Kippelen and J.-L. Brédas, “Organic photovoltaics,” Energy \& Environmental Science, vol. 2, no. 3, p. 251, 2009.

[3] S. H. Park, A. Roy, S. Beaupré, S. Cho, N. Coates, J. S. Moon, D. Moses, M. Leclerc, K. Lee, and A. J. Heeger, "Bulk heterojunction solar cells with internal quantum efficiency approaching 100\%,” Nat Photon, vol. 3, no. 5, pp. 297-302, May 2009.

[4] N. S. Sariciftci, L. Smilowitz, A. J. Heeger, and F. Wudl, "Photoinduced electron transfer from a conducting polymer to buckminsterfullerene,” Science, vol. 258, no. 5087, pp. 14741476, Nov. 1992.

[5] N. S. Sariciftci, D. Braun, C. Zhang, V. I. Srdanov, A. J. Heeger, G. Stucky, and F. Wudl, "Semiconducting polymer-buckminsterfullerene heterojunctions: Diodes, photodiodes, and photovoltaic cells,” Applied Physics Letters, vol. 62, no. 6, p. 585, 1993.

[6] N. S. Sariciftci, "Polymeric photovoltaic materials," Current Opinion in Solid State and Materials Science, vol. 4, no. 4, pp. 373-378, Aug. 1999.

[7] C. J. Brabec, N. S. Sariciftci, and J. C. Hummelen, "Plastic solar cells," Adv. Funct. Mater., vol. 11, no. 1, pp. 15-26, 2001.

[8] J. Nelson, "Organic photovoltaic films," Current Opinion in Solid State and Materials Science, vol. 6, no. 1, pp. 87-95, Feb. 2002.

[9] H. Hoppe and N. S. Sariciftci, “Organic solar cells: An overview,” Journal of Materials Research, vol. 19, no. 07, pp. 1924-1945, 2004.

[10] W. Li, A. Furlan, K. H. Hendriks, M. M. Wienk, and R. A. J. Janssen, "Efficient Tandem and Triple-Junction Polymer Solar Cells,” J. Am. Chem. Soc., vol. 135, no. 15, pp. 55295532, Apr. 2013.

[11] R. F. Service, “Outlook Brightens for Plastic Solar Cells,” Science, vol. 332, no. 6027, pp. 293-293, Apr. 2011.

[12] N. Martín, L. Sánchez, B. Illescas, and I. Pérez, “C60-Based Electroactive Organofullerenes,” Chem. Rev., vol. 98, no. 7, pp. 2527-2548, Nov. 1998.

[13] M. Prato, “[60]Fullerene chemistry for materials science applications,” J. Mater. Chem., vol. 7, no. 7, pp. 1097-1109, Jan. 1997.

[14] H. N. Ghosh, A. V. Sapre, and J. P. Mittal, “Aggregation of C70 in Solvent Mixtures,” J. Phys. Chem., vol. 100, no. 22, pp. 9439-9443, Jan. 1996.

[15] V. N. Bezmelnitsin, A. V. Eletskii, and E. V. (Russian S. C. K. I. Stepanov, "Cluster Origin of Fullerene Solubility,” Journal of Physical Chemistry; (United States), vol. 98:27, Jul. 1994.

[16] R. V. Bensasson, E. Bienvenue, M. Dellinger, S. Leach, and P. Seta, "C60 in Model Biological Systems. A Visible-UV Absorption Study of Solvent-Dependent Parameters and Solute Aggregation,” J. Phys. Chem., vol. 98, no. 13, pp. 3492-3500, Mar. 1994.

[17] B. H. Johnson, E. Allagoa, R. L. Thomas, G. Stettler, M. Wallis, J. H. Peel, T. Adalsteinsson, B. J. McNelis, and R. P. Barber Jr., "Influence of functionalized fullerene structure on polymer photovoltaic degradation,” Solar Energy Materials and Solar Cells, vol. 94, no. 3, pp. 537-541, Mar. 2010.

[18] E. L. Sena, J. H. Peel, D. Wesenberg, S. Nathan, M. Wallis, M. J. Giammona, T. Adalsteinsson, B. J. McNelis, and R. P. Barber Jr, “Transport and spectroscopic studies of 
the effects of fullerene structure on the efficiency and lifetime of polythiophene-based solar cells," Solar Energy Materials and Solar Cells, vol. 100, pp. 192-198, 2012.

[19] N. C. Miller, R. Gysel, C. E. Miller, E. Verploegen, Z. Beiley, M. Heeney, I. McCulloch, Z. Bao, M. F. Toney, and M. D. McGehee, "The phase behavior of a polymer-fullerene bulk heterojunction system that contains bimolecular crystals," Journal of Polymer Science Part B: Polymer Physics, vol. 49, no. 7, pp. 499-503, 2011.

[20] R. Peng, J. Zhu, W. Pang, Q. Cui, F. Wu, K. Liu, M. Wang, and G. Pan, “Thermal Annealing Effects on the Absorption and Structural Properties of Regioregular Poly(3Hexylthiophene) Films,” Journal of Macromolecular Science, Part B, vol. 50, no. 3, pp. 624-636, 2011.

[21] J. D. Perkins, M. P. Taylor, M. F. A. M. van HEST, C. W. Teplin, J. L. Alleman, M. S. Dabney, L. M. Gedvilas, B. M. Keyes, B. To, D. W. Readey, A. E. Delahoy, S. Guo, and D. S. Ginley, "Combinatorial optimization of transparent conducting oxides (TCOs) for PV," in Conference Record of the Thirty-first IEEE Photovoltaic Specialists Conference, 2005, 2005, pp. $145-147$.

[22] A. Teichler, R. Eckardt, S. Hoeppener, C. Friebe, J. Perelaer, A. Senes, M. Morana, C. J. Brabec, and U. S. Schubert, "Combinatorial Screening of Polymer:Fullerene Blends for Organic Solar Cells by Inkjet Printing," Advanced Energy Materials, vol. 1, no. 1, pp. 105114, 2011.

[23] D. K. Susarova, E. A. Khakina, P. A. Troshin, A. E. Goryachev, N. S. Sariciftci, V. F. Razumov, and D. A. M. Egbe, "Photovoltaic performance of PPE-PPV copolymers: effect of the fullerene component,” J. Mater. Chem., vol. 21, no. 7, pp. 2356-2361, Feb. 2011.

[24] Y.-C. Lai, T. Higashihara, J.-C. Hsu, M. Ueda, and W.-C. Chen, "Enhancement of power conversion efficiency and long-term stability of P3HT/PCBM solar cells using C60 derivatives with thiophene units as surfactants," Solar Energy Materials and Solar Cells, vol. 97, pp. 164-170, Feb. 2012.

[25] N. J. Jeon, H. G. Lee, Y. C. Kim, J. Seo, J. H. Noh, J. Lee, and S. I. Seok, “o-Methoxy Substituents in Spiro-OMeTAD for Efficient Inorganic-Organic Hybrid Perovskite Solar Cells,” J. Am. Chem. Soc., vol. 136, no. 22, pp. 7837-7840, Jun. 2014. 


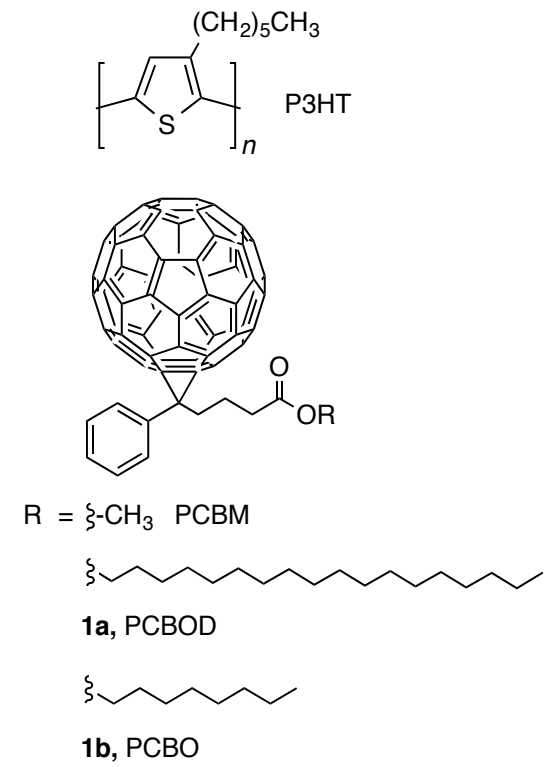



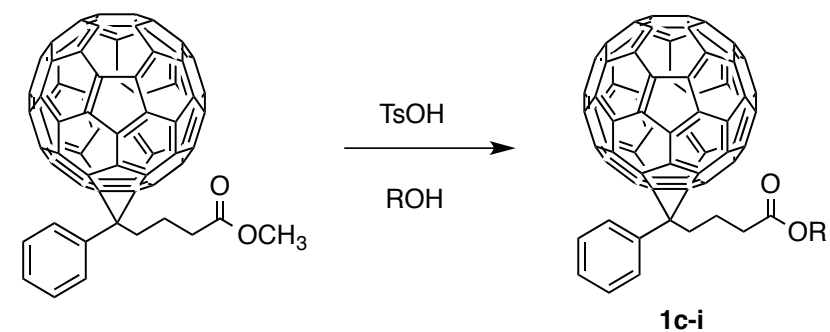

R:

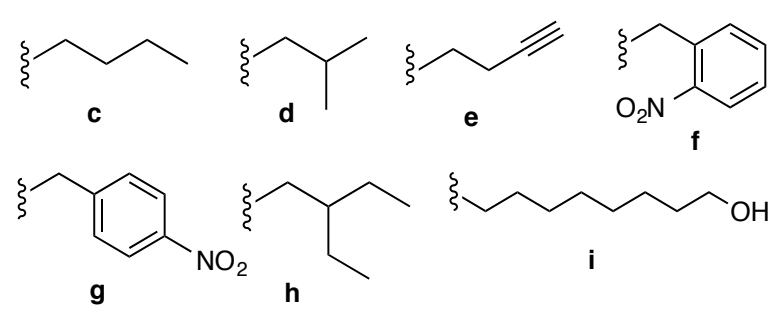




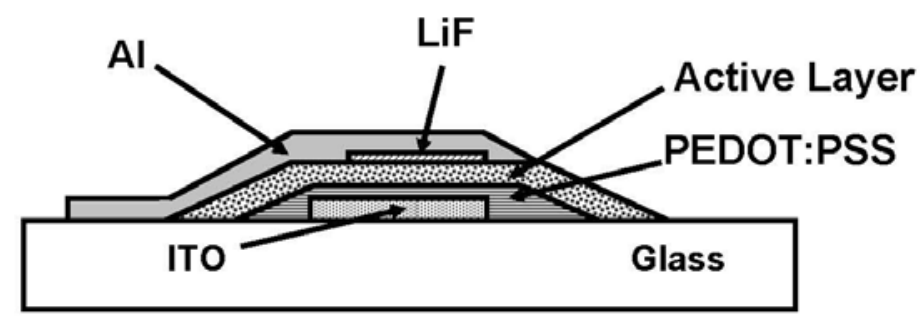

Fig 1 


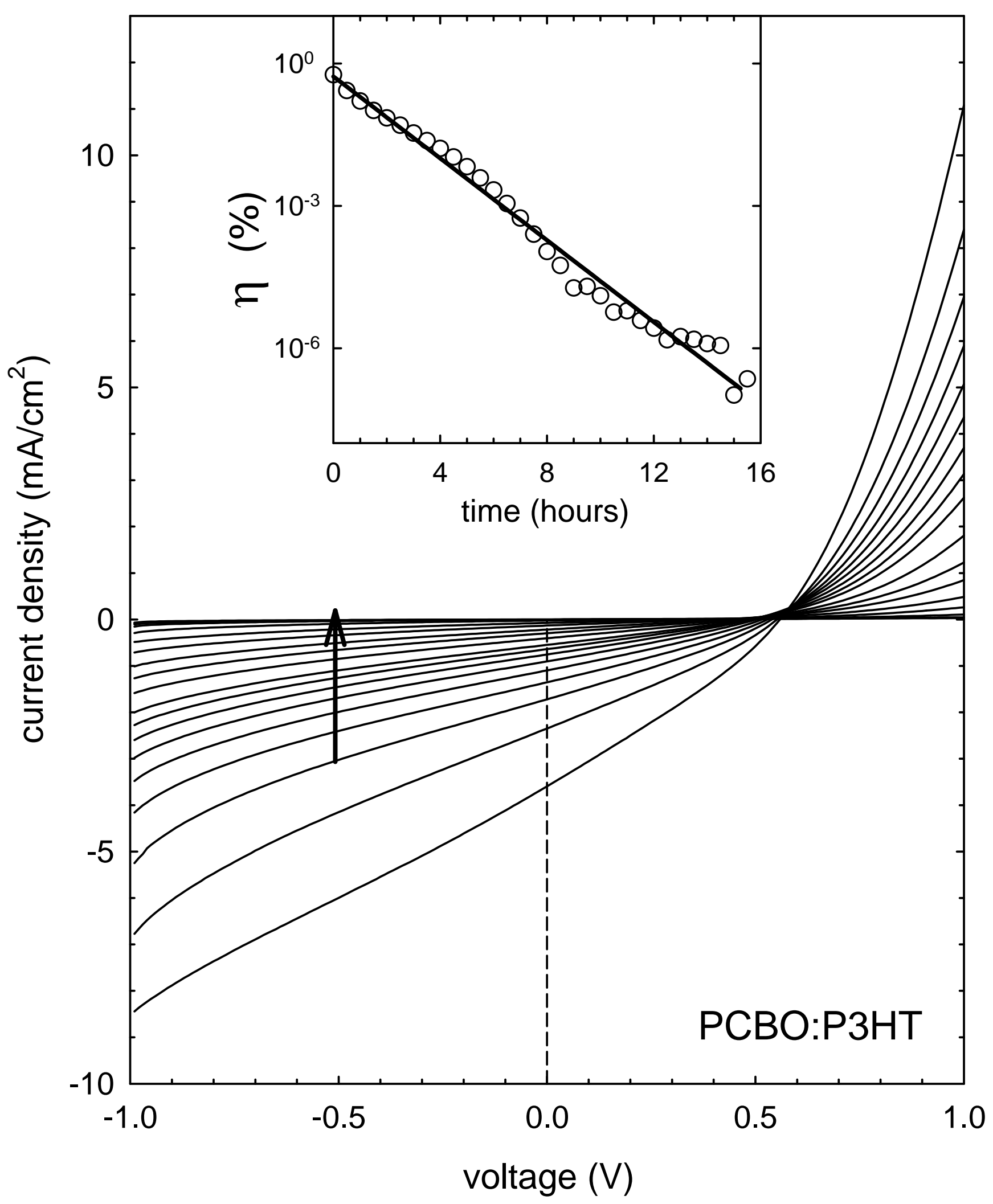

Fig. 3 


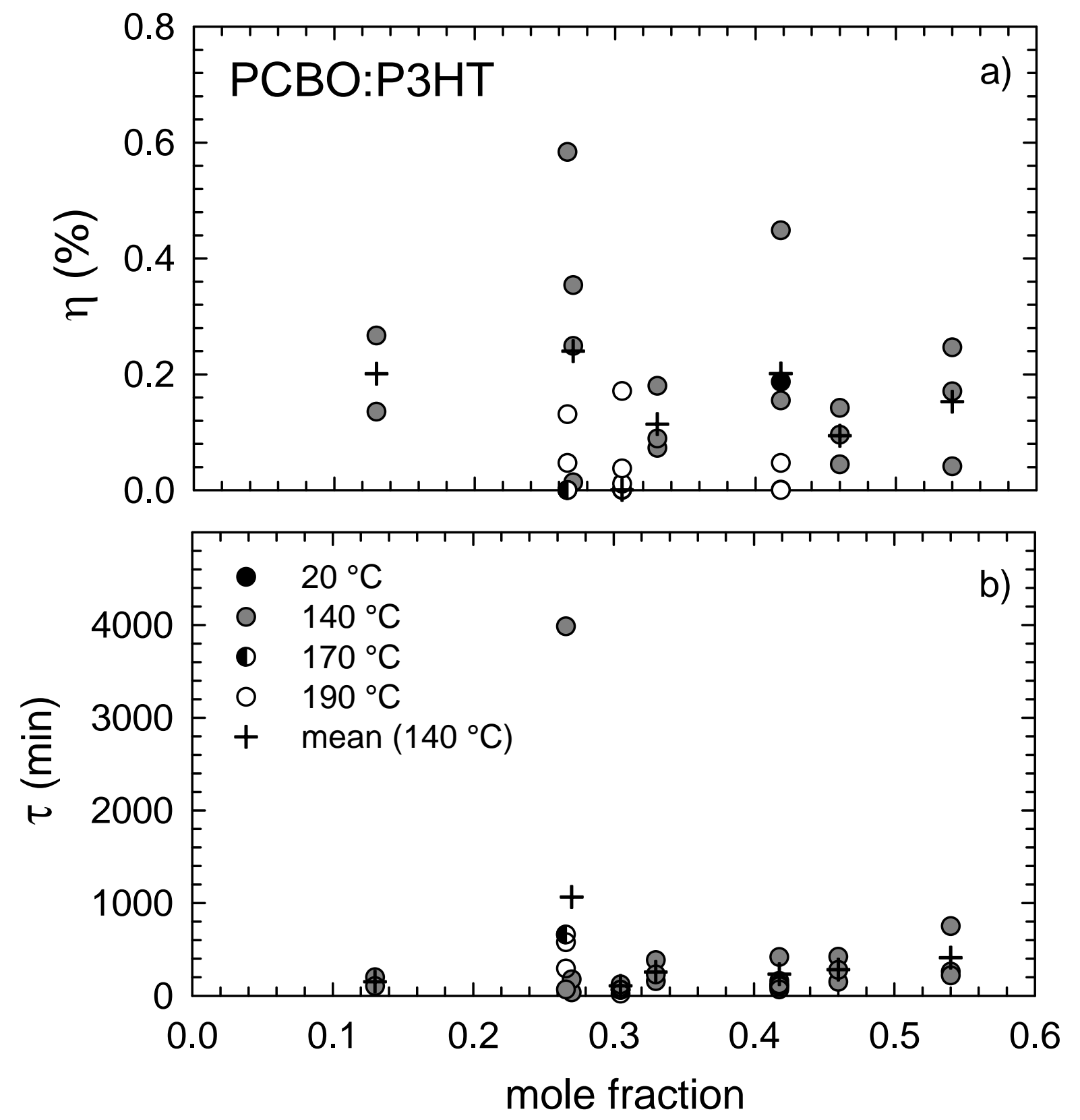

Fig. 4 

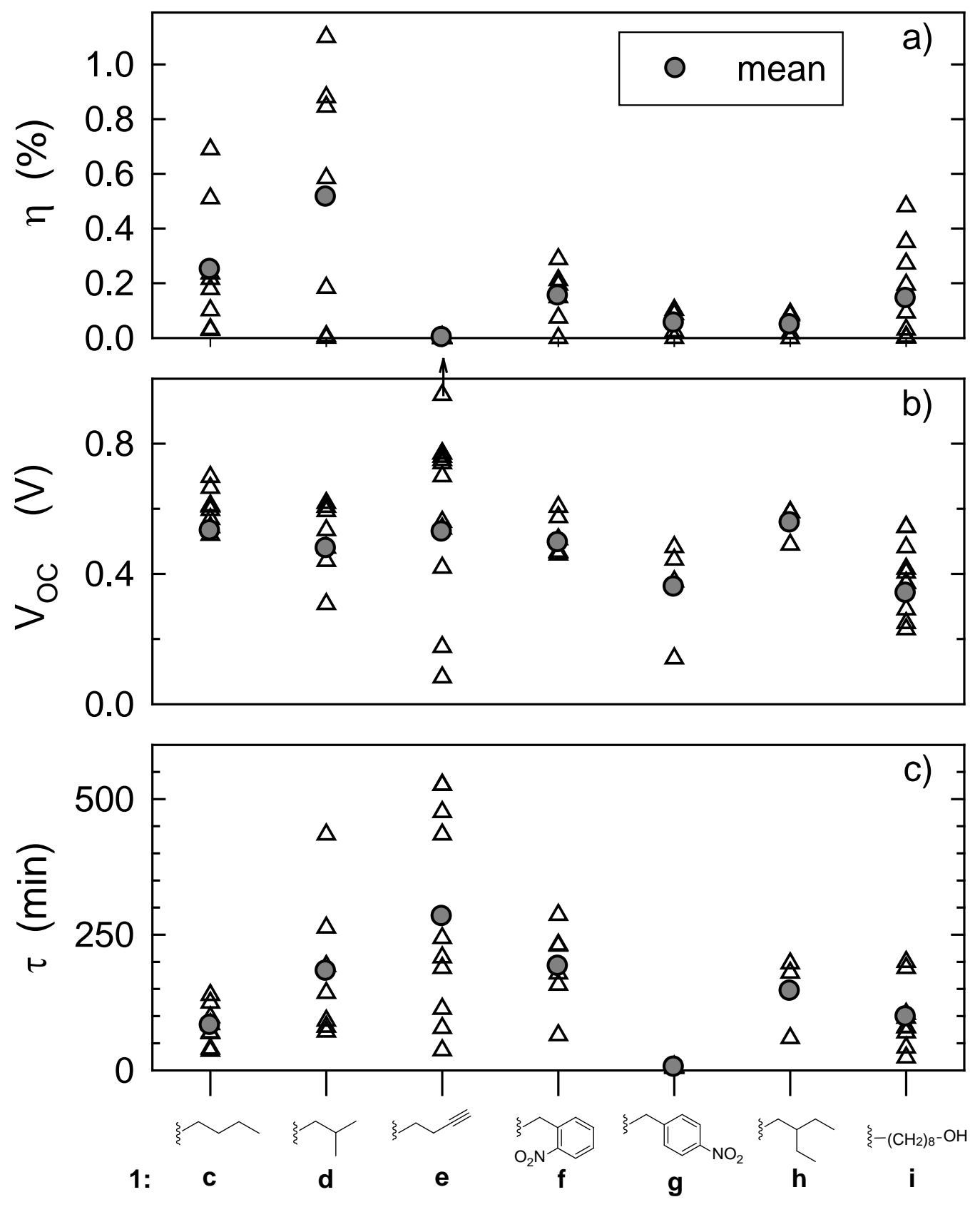


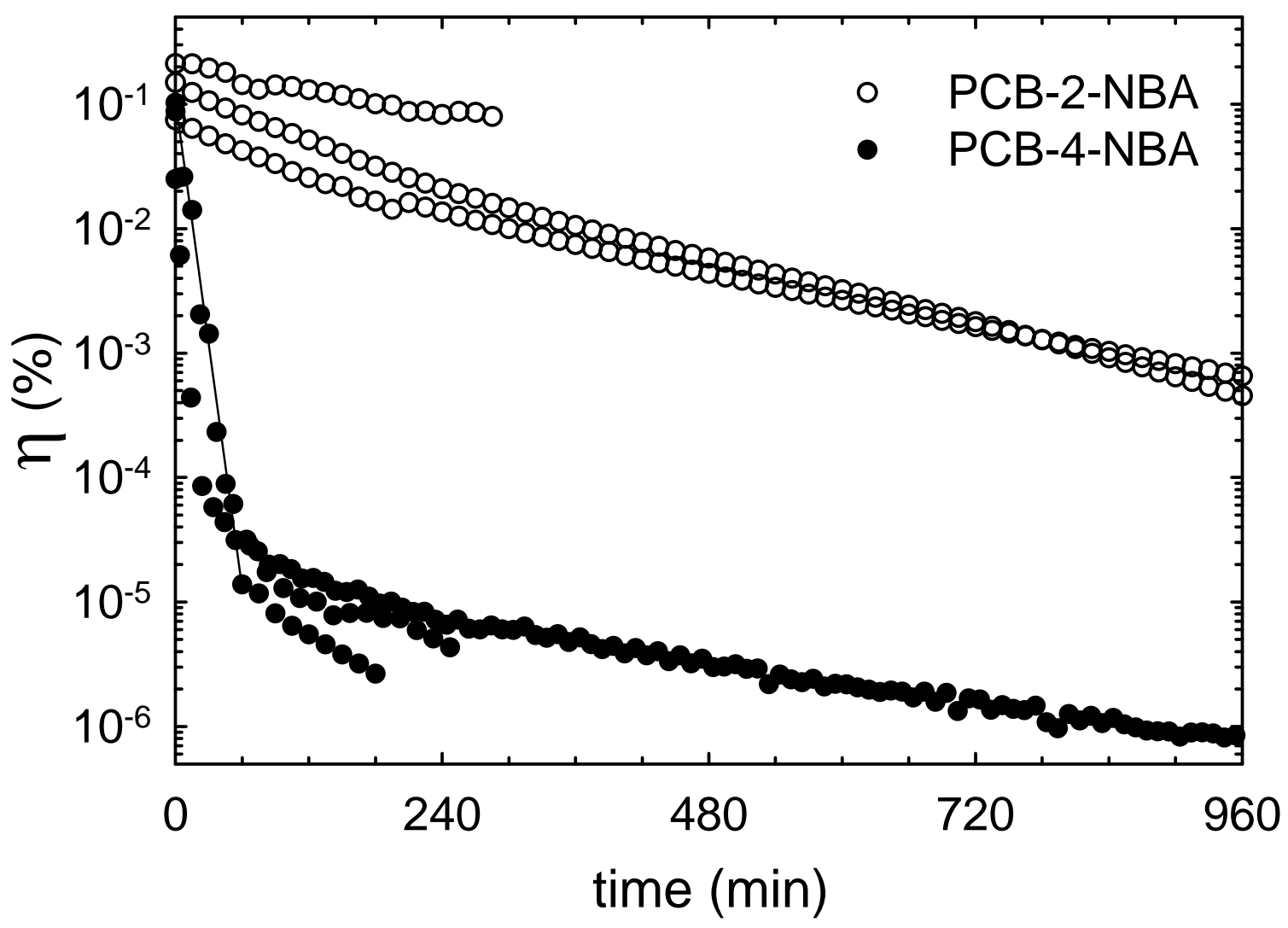

Fig. 6 

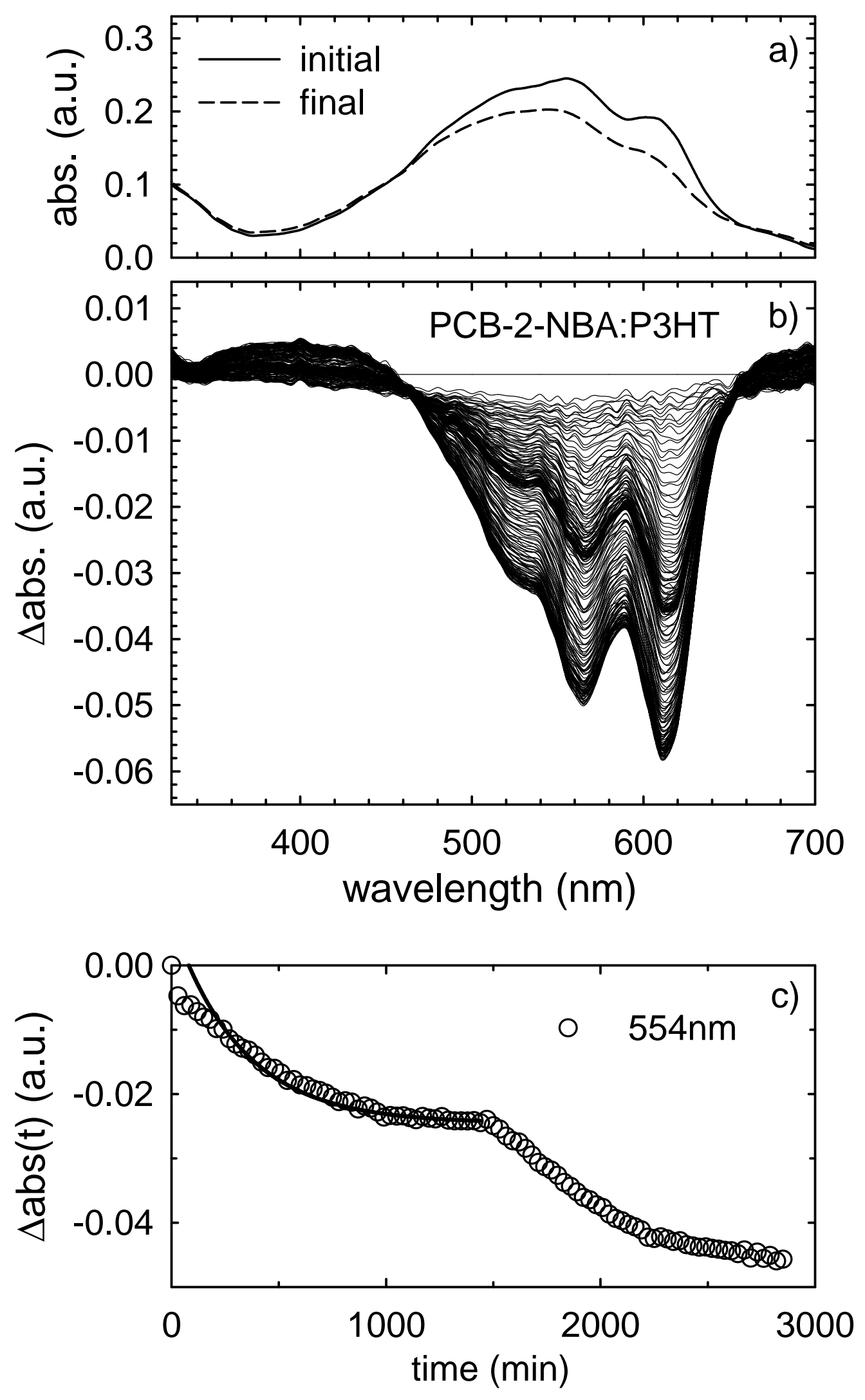

Fig. 7 